\title{
MJN A STUDY ON HEART FAILURE EDUCATION PRINCIPLES: ARE NURSES EQUIPPED WITH KNOWLEDGE?
}

\author{
Yee Bit-Lian*, Tan Woei-Ling, Lee Yuen-Leng \\ International Medical University, Malaysia \\ *Corresponding Author's Email: bitlianyee@imu.edu.my
}

\begin{abstract}
Introduction: Approximately 3-20/1000 Malaysians are suffering from heart failure. Nurses are in the frontline to provide heart failure patient education to make a significant difference to the patient's health outcomes. The objectives of the study are to assess the registered nurses' knowledge of heart failure education principles and its association between demographic data, and knowledge of heart failure education principles among registered nurses' in a private hospital, Perak, Malaysia. Methods: A crosssectional, descriptive study was conducted among 140 participants. Nurse Knowledge of Heart Failure Education Principles (NKHFEP) survey was adopted and used. Results: Total mean score was 12.94 (SD = 2.201), which suggested there were gaps in nurses' knowledge in heart failure education principles. Questions which achieved total correct response scores of $>90 \%$ were: drinking fluids when thirsty, fatigue and leg weakness/low exercise tolerance. Total correct response scores of $<30 \%$ were: dry weight, asymptomatic low BP and dizziness. There was significant association between nurses' heart failure knowledge to the participants' demographic variables were working department, working experience and nursing qualifications. Conclusion: Registered nurses have inadequate knowledge in heart failure education principles. Nurses need to have strong knowledge on self-management principles which would have potential impact on reducing hospital re-admission, improving quality of life and increase patient satisfaction.
\end{abstract}

Keywords: Registered Nurses, Knowledge, Heart Failure, Education Principles

\section{INTRODUCTION}

It is estimated that heart failure affects at least 26 million people globally (Savarese \& Lund, 2017). Study found that heart failure patients who undergo the surgery are exposed to significant perioperative complications and high mortality (Cowie et al., 2000; Pichette et al., 2017). Recently, Ministry of Health Malaysia (2019) reported that approximately 3-20/1000 Malaysians are suffering from heart failure. However, for Malaysians over 60 years old, the figure reaches as high as 100/1000. Hence, around $6-10 \%$ of acute hospital admissions are caused by heart failure. It was reported that $25 \%$ of the heart failure patients are readmitted within 30 days. In a metropolitan city of Kuala Lumpur, a study by Chong et al., (2003) reported that out of total of 1,435 patients who were admitted to one of the prestigious private hospital with acute conditions, 6.7\% (97 patients) were diagnosed with heart failure.

In the state of Perak (where the study was conducted), Malaysia, the population stands at $2,352,743$, with the populations aged 60 years and above numbered at 274,006 (Malaysia City Population, 2010). The population aged 60 and above represents $12 \%$ of the total population in Perak. Based on this background, Hospital A, a private hospital in Perak, has an average rate of $7 \%$ of heart failure admissions including the newly diagnosed as well as known cases every month. From the statistics, heart failure is a major public health problem and poses a huge risk, especially to the aging group. Therefore, heart failure management and patient education must be given more attention specially in the case of aging group. Heart failure patient education is intended to break the cycle of readmission, alleviate 
symptoms and better quality of life (Albert et al., 2002).

Heart failure patient education relates to nonpharmacological measures which include directed heart failure counselling to the patients and families; routine exercise; dietary and fluid intake; and appropriate lifestyle changes. Although prevention and early intervention remain as the primary goal in heart failure management in clinical practice guidelines (CPG) (MOH, 2014), non-pharmacological measures in case of heart failure patient including education may enhance and make a significant difference to the patient's health outcomes. In this regard, the nurses who tend to care for heart failure patients have a significant role as they often are the frontline position to provide heart failure patient education.

Many studies emphasized that the nurses' knowledge in heart failure education principles must first be identified, before any interventions aimed at enhancing an individual's proficiency. Those of importance were senior nurses to educate themselves continuously (Albert, 2013; Jonkowska-Polanska et al., 2017), to include heart failure education principles as a specific topic (Jonkowska-Polanska et al., 2017), training and development program to achieve optimum level in heart failure education (Albert et al., 2002; Fowler, 2012; Sundel \& Ea, 2018; Willette et al., 2007), which ultimately improves heart failure patients' health, quality of life and reduced chances of readmission (Butrous \& Hummel, 2016; Sterne et al., 2014).

The purpose of this study is to assess the registered nurses' knowledge of heart failure education principles; and to determine if there is association between demographic data and knowledge on heart failure education principles among the registered nurses in the private hospital in Perak, Malaysia.

\section{METHODOLOGY}

\section{Study design}

This was a cross-sectional and descriptive study to examine the registered nurses' knowledge on heart failure education principles in a private hospital in Perak, Malaysia. A convenience sampling method was used in this study. These registered nurses were from medical, surgical and all specialized wards including Critical Care Unit, High Dependency Unit, Cardiac Catheterization Unit, Chemotherapy Daycare Unit, Maternity Ward, Hemodialysis Department and Emergency Department.

\section{Participants}

A total of 140 staff nurses from the aforementioned departments and wards in Hospital A were involved in the study after they fulfilled the inclusion criteria. The inclusion criteria included all registered male or female nurses who are working in Hospital A; registered nurses who volunteer to participate in the study and who render direct care to the heart failure patients. The exclusion criteria included registered nurses who are foreigners and who do not render direct care to the heart failure patients such as Paediatric ward nurses and Operation Theatre nurses.

\section{Instrument}

Nurse Knowledge of Heart Failure Education Principles (NKHFEP) survey was used. The questionnaire consists of two parts. This was adopted for this research study and consent was obtained from Albert et al., (2002). Part 1 consists of questions seeking demographic information regarding registered nurse's age, gender, current working department, educational qualifications, working experiences, nursing classifications and whether they had given any health education on heart failure before. Part 2 consists of questionnaires on twenty true/false statements concerning five important educational principles of heart failure self-management: fluids and weight (7 statements), diet (3 statements), signs or symptoms of worsening condition ( 6 statements), exercise ( 2 statements) and medications ( 2 statements).

The essence of the questionnaire was verified by the Director of Nursing, Nursing Educator and CCU Nursing Manager. The panel of experts has evaluated the validity of the contents and its suitability, such as the language and wordings of the questionnaire used in this study. The Cronbach's alpha obtained 0.94 which shows evidence of good reliability of our study. Value of 0.70 or higher is treated as good (Polit \& Beck, 2017).

\section{Ethical considerations}

Submission of the proposal for approval to the ethical committee of International Medical University (IMU) was done prior to commencement of the study. Permission was also obtained from the Medical Director and Director of Nursing of Hospital A, Perak, Malaysia prior to the study. Once the approval was received, the ward managers of the selected wards and departments were informed about the study and consent was obtained from the ward managers to carry out the research. 
Thereafter, the registered nurses were invited to participate in the study. Participating registered nurses were then given instructions for the questionnaire. Thirty minutes' time was given to the registered nurse to answer the questionnaire. Once the questionnaire has been completed, it was returned to the researcher. The participation was voluntary, and their identities were kept anonymous and confidential.

\section{Data analysis}

All the data was entered into the Statistical Package for the Social Sciences (SPSS) Version 24.0. The description of the demographic data and 20-item questionnaire were carried out using descriptive statistics included mean, median, percentage and standard deviation (SD). Demographic data was presented in the form of bar chart or tables. They comprised of the registered nurses' age, gender, current working department, educational qualifications, working experiences, nursing classifications and whether they had given any health education on heart failure before.

The inferential data was used to analyse the significant differences between social demographic data and the registered nurses' knowledge on heart failure education principles. The inferential analysis for the Independent $t$-test was used to compare gender and whether any health education on heart failure was given before in relation to heart failure education principles. ANOVA was used to compare the means for age, current working department, educational qualifications, working experience and nursing classifications. Data analysis with the level of significance ( $p$-value) will be set at $\leq 0.05$. If the $p$-value is obtained less than 0.05 , alternative hypothesis will be accepted as there's dissimilarity between means (Polit \& Beck, 2017).

\section{RESULTS}

\section{Demographic variables}

The age of the participants ranged from 21 to 67 years with mean of $31.41(\mathrm{SD}=7.789)$. As shown in the Table $1,79(56.4 \%)$ nurses were aged below 30 years old and 61 (43.6\%) nurses were aged above 30 years old. Predominantly the nurses were female $(n=135,96.4 \%)$. In regard to educational qualifications, majority were Diploma holders $(\mathrm{n}=112,80 \%)$ and one Master holder $(0.7 \%)$. As for working experience, majority have more than five years working experience $(n=79,56.4 \%)$, with mean of $7.82(\mathrm{SD}=6.810)$. For the nursing classification: $120(85.7 \%)$ were registered nurses, one nurse educator $(0 / 7 \%)$, five clinical instructors and seven charge nurses with $3.6 \%$ and $5 \%$ respectively. Only half of them $(n=$ $70,50 \%$ ) claimed that they were given heart failure patient education during their nursing career.

Table 1: Demographic Data of Registered Nurses

\begin{tabular}{|c|c|c|}
\hline Variables & $\mathbf{N}$ & $\mathbf{M} \pm \mathbf{S D}$ \\
\hline Age (years) & & $31.41 \pm 7.789$ \\
\hline$\leq 30$ & $79(56.4 \%)$ & $12.96 \pm 2.175$ \\
\hline$>30$ & $61(43.6 \%)$ & $12.92 \pm 2.253$ \\
\hline \multicolumn{3}{|l|}{ Gender } \\
\hline Female & $135(96.4 \%)$ & $12.93 \pm 2.220$ \\
\hline Male & $5(3.6 \%)$ & $13.20 \pm 1.789$ \\
\hline \multicolumn{3}{|l|}{ Working department } \\
\hline Critical Care Unit & $19(13.6 \%)$ & $13.05 \pm 2.321$ \\
\hline Emergency Department & $12(8.6 \%)$ & $12.83 \pm 1.467$ \\
\hline Haemodialysis Day Care & $11(7.9 \%)$ & $13.64 \pm 1.286$ \\
\hline Chemotherapy Day Care & $5(3.6 \%)$ & $16.20 \pm 1.095$ \\
\hline Maternity Ward & $8(5.7 \%)$ & $11.88 \pm 3.834$ \\
\hline Diagnostic Centre & $8(5.7 \%)$ & $13.13 \pm 2.532$ \\
\hline Surgical Ward & $10(7.1 \%)$ & $14.10 \pm 1.853$ \\
\hline Medical Ward & $13(9.3 \%)$ & $13.77 \pm 1.536$ \\
\hline Multidisciplinary Ward & $18(12.9 \%)$ & $12.33 \pm 2.142$ \\
\hline Orthopedic Ward & $21(15 \%)$ & $11.71 \pm 2.077$ \\
\hline Neuroscience Ward & $13(9.3 \%)$ & $12.77 \pm 1.481$ \\
\hline Nursing Administrative & $2(1.4 \%)$ & $12.50 \pm 2.121$ \\
\hline \multicolumn{3}{|l|}{ Educational Qualifications } \\
\hline Diploma & $112(80 \%)$ & $12.79 \pm 2.032$ \\
\hline Bachelor's degree & $27(19.3 \%)$ & $13.63 \pm 2.748$ \\
\hline Master & $1(0.7 \%)$ & $11 \pm 0$ \\
\hline \multicolumn{2}{|l|}{ Working Experience } & $7.82 \pm 6.810$ \\
\hline$\leq 5$ & $61(43.6 \%)$ & $12.59 \pm 1.764$ \\
\hline$>5$ & $79(56.4 \%)$ & $13.22 \pm 2.463$ \\
\hline \multicolumn{3}{|l|}{\begin{tabular}{|l} 
Nursing Classifications \\
\end{tabular}} \\
\hline Registered Nurse & $120(85.7 \%)$ & $12.77 \pm 2.153$ \\
\hline Nurse Educator & $1(0.7 \%)$ & $11 \pm 0$ \\
\hline Nurse Manager & $7(5 \%)$ & $13.57 \pm 1.988$ \\
\hline Associate Charge Nurse & $7(5 \%)$ & $15.14 \pm 2.734$ \\
\hline Clinical Nursing Instructor & $5(3.6 \%)$ & $13.60 \pm 1.342$ \\
\hline \multicolumn{3}{|l|}{$\begin{array}{l}\text { Given Health Education on } \\
\text { Heart Failure }\end{array}$} \\
\hline Yes & $70(50 \%)$ & $12.94 \pm 2.035$ \\
\hline No & $70(50 \%)$ & $12.94 \pm 2.371$ \\
\hline
\end{tabular}

Table 2 below shows the percentages of total correct responses to single questions that scored $>90 \%$. A total of four statements achieved individual scores of $>90 \%$. They are "Patients with heart failure should drink plenty of fluids each day", "When fluid limitations are ordered, it is OK to remove the limits when patient feel thirsty", "New onset or worsening of fatigue" and "New onset of worsening leg weakness or decreased ability to exercise". 
Table 2: Individual Statements with Aggregate Correct Scores $>90 \%$

\begin{tabular}{|l|l|c|}
\hline Question & Topic & $\begin{array}{c}\text { Score } \\
(\%)\end{array}$ \\
\hline 1. & $\begin{array}{l}\text { "Patients with heart failure should drink plenty of } \\
\text { fluids each day." }\end{array}$ & $95 \%$ \\
\hline 10. & $\begin{array}{l}\text { "When fluid limitations are ordered, it is OK to } \\
\text { remove the limits when patient feel thirsty." }\end{array}$ & $94.3 \%$ \\
\hline 19. & "New onset or worsening of fatigue. . & $97.9 \%$ \\
\hline 20. & $\begin{array}{l}\text { "New onset of worsening leg weakness or decreased } \\
\text { ability to exercise." }\end{array}$ & $97.1 \%$ \\
\hline
\end{tabular}

Table 3 below shows the percentages of total correct responses to individual questions that scored $<30 \%$. A total of three statements achieved individual scores of $<30 \%$. They are "When assessing weight results, today's weight should be compared with the patient's weight from yesterday, not the patient's ideal or dry weight", "BP recording of 80/56 without any heart failure symptoms" and "Dizziness or light-headedness when arising that disappears within 5 minutes".

Table 3: Individual Statements with Aggregate Correct Responses $<30 \%$

\begin{tabular}{|c|l|c|}
\hline Question & Topic & $\begin{array}{l}\text { Score } \\
\mathbf{( \% )}\end{array}$ \\
\hline 15. & $\begin{array}{l}\text { "When assessing weight results, today's weight } \\
\text { should be compared with the patient's weight } \\
\text { from yesterday, not the patient's ideal or dry } \\
\text { weight." }\end{array}$ & $17.9 \%$ \\
\hline 16. & $\begin{array}{l}\text { "BP recording of 80/56 without any heart failure } \\
\text { symptoms." }\end{array}$ & $28.6 \%$ \\
\hline 18. & $\begin{array}{l}\text { "Dizziness or light-headedness when arising that } \\
\text { disappears within 5 minutes." }\end{array}$ & $26.4 \%$ \\
\hline
\end{tabular}

ANNOVA test was used to measure the association for variables working department,education qualifications and nursing classifications. Inferential analysis of Independent $t$-test was used to measure the association for variables age, gender, working experienceand whether the participants have given any heart failure patient education before. Table 4 below shows the association between demographic data and knowledge on heart failure education principles among registered nurses. There appears to be no significant association between the registered nurses' age, gender, educational qualifications and whether or not they had given any heart failure patient education before, and the registered nurses' knowledge on heart failure education principles with $p$-values of $0.493,0.646$, 0.141 and 0.527 respectively, as $p$-value of $>0.05$ indicates insignificant association. On the other hand, $p$-value of $<0.05$ was found on demographic data relating to the registered nurses' working department, working experience and nursing classifications in relation to the registered nurses' knowledge on heart failure education principles with $p$-values of 0.003 , 0.049 and 0.046 respectively. Therefore, it appears to show positive association among these variables as $p$ value was $<0.05$.

Table 4: Association between Demographic Data and Knowledge on heart failure Education Principles among Registered Nurses

\begin{tabular}{|l|c|}
\hline Variables & p-value \\
\hline Age (years) & 0.493 \\
\hline Gender & 0.646 \\
\hline Working department & $\mathbf{0 . 0 0 3 *}$ \\
\hline Education Qualifications & 0.141 \\
\hline Working Experience & $\mathbf{0 . 0 4 9}$ \\
\hline Nursing Classifications & $\mathbf{0 . 0 4 6 *}$ \\
\hline Given any heart failure patient education before & 0.527 \\
${ }^{*} p$-value $<0.05$ indicates significant association \\
$* * p$-value $>0.05$ indicates insignificant association
\end{tabular}

\section{DISCUSSION}

\section{Knowledge on Heart Failure Education Principles}

Nurses play a particularly important role in heart failure patients' education. Nurses must have sufficient knowledge of heart failure self-management principles in order to successfully educate heart failure patients on self-management skills. Roussel (2015) admitted the pivotal role of nurses in patient education and emphasized that sufficient nurses' knowledge of heart failure education principles is fundamental towards a successful patient-family counselling. According to the findings, the mean score of knowledge on heart failure education principles among registered nurses in the private hospital in Ipoh, Malaysia is 12.94 with SD of 2.201 which represents $64.7 \%$. Our findings also shared similar scores by other studies. In the study done by Jankowska-Polanska et al., (2017) on Polish nurses the mean score was $12.1(\mathrm{SD}=2.7)$ representing $60.4 \%$, which shows Polish nurses' knowledge deficit in heart failure education principles. In addition, the mean score obtained in the study by Albert et al., (2002) was 15.2 $(\mathrm{SD}=2)$, in Washburn et al., (2005) study the mean score was $14.6(\mathrm{SD}=2)$, whereas in Kalogirou et al., (2012) study obtained a mean score of 13.57 $(\mathrm{SD}=2.33)$. The results from these studies concluded that there is lack of knowledge on heart failure education principles among these nurses.

Individual statements with aggregate scores $>90 \%$ Based on the findings obtained in this research, there are 
four statements which obtained scores above $90 \%$ with correct responses. Firstly, the statement "Patients with heart failure should drink plenty of fluids each day" scored 95\%, the study done by Albert et al., (2002) also obtained similar result on the statement which scored $93.7 \%$. The doctor in-charged of heart failure will usually instruct fluid restriction for patient's by writing on the treatment chart the amount of fluids to be limited to prevent overload.

Second statement which had a total score of $>90 \%$ is "When fluid limitations are ordered, it is $\mathrm{OK}$ to remove the limits when patient feel thirsty" (94.3\%). Similar finding was obtained in the study of Albert et al., (2002) on the statement which scored $98.3 \%$. In this Hospital A setting, intake and output chart were used to monitor the amount of fluids consumed and amount of output obtained. In addition, water jug or bottle will be prefilled daily according to the patient's fluid restriction.

The third statement "New onset or worsening of fatigue" and forth statement "New onset of worsening leg weakness or decreased ability to exercise" also shared similar scores to the study by Albert et al., (2002), Sterne et al., (2014) and Jankowska-Polanska et al., (2017), all of whom scored more than $90 \%$. Heart failure patients are encouraged to notify any abnormality to the nurses which may include increased breathlessness, increased tiredness or weakness to the lower limbs and reduced ability in light activities. This way the perceived abnormalities can be reported by the nurses to the doctor in charge. The total of single item correct responses (sums correct response) were computed and expressed in percentage. High correct response statements were identified. The threshold of $90 \%$ was used as it is consistent with the surveys of Washburn et al., (2005) and Jankowska-Polanska et al., (2017).

\section{Individual Statements with Aggregate Scores $<30 \%$}

According to this research findings, there were three statements which obtained scores of $<30 \%$. They are:

"When assessing weight results, today's weight should be compared with the patient's weight from yesterday, not the patient's ideal or dry weight"; "BP recording of 80/56 without any heart failure symptoms"; and "Dizziness or light-headedness when arising that disappears within 5 minutes". The results obtained are all similar to the previous studies done by JankowskaPolanska et al., (2017), Sterne et al., (2014), Fowler (2012), Washburn et al., (2005) and Albert et al., (2002). When weight of a patient has normal jugular venous pressure and absent of worsening or new rales, S3 heart sound or edema, it is known as "dry" weight and it is not the same as ideal weight on the basis of bone structure and height (Sulzbach-Hoke et al., 1997). When heart failure patients gained weight but do not display any worsening or new symptoms, it is more appropriate to use "dry" weight for monitoring. Hence, patients who lack proper heart failure education on weight monitoring may fail to accurately assess the increase in current weight and fail to report to notify their doctors accordingly. Daily weight measurement for all heart failure patient is essential except for unfit patients who cannotbe weighed.

Albert et al., (2002) reported that more than 70\% of the surveys, nurses failed to report symptoms related to non-symptomatic, low blood pressure and dizziness. The findings found that the nurses' lacked knowledge regarding the said patient's symptoms due to the inadequacy of knowledge in heart failure pathophysiology and objectives of treatment. The total of single statements with correct responses (sums of correct response) were computed and presented in percentage. Statements with low correct responses were identified. The threshold of $30 \%$ was used as it is consistent with the findings of Washburn et al., (2005) and Jankowska-Polanska et al., (2017).

Association between demographic data and knowledge on heart failure education principles among registered nurses

\section{(a) Working Department and Knowledge on Heart Failure Education Principles}

Chemotherapy day care (CDC) department scored the highest with a mean score of 16.20 , followed by surgical ward a mean score of 14.10 and hemodialysis department with a mean score of 13.64. $P$-value obtained was 0.003 which shows that there is association between working department and knowledge on heart failure education principles. The researcher is of the view that CDC registered nurses performed better compared with the other departments because they are more enthusiastic and record shows that CDC was awarded as the exemplary department for three years consecutively. One possible explanation for surgical ward's second highest score may be due to the ward nurses' line of work which involves preoperative and postoperative optimization for patients going for surgery. As optimization interventions require competent knowledge relating to fluid and weight management and medications from the ward nurses, their level of knowledge on heart failure in general are above average compared with most of the nurses from other departments. HDC registered nurses had the third highest score and this may be due to the 
similarity between haemodialysis patient-care and heart failure patient-care. Renal care focuses on weight management, blood pressure management, diabetes management, nutritional health and medication safety, are all pertinent to heart failure self-management principles (Havas, Bonner \& Douglas, 2016).

\section{(b) Working Experience and Knowledge on Heart Failure Education Principles}

Registered nurses who have $>5$ years of working experience had a higher mean score of 13.22 whereas registered nurses who have $<5$ years of working experience had a lower mean score of 12.59. The $p$-value obtained was 0.049 , it shows an association between working experience and knowledge on heart failure education principles. Based on the data collected, the researcher is of the view that the senior nurses in this private hospital are more proactive in updating their medical knowledge compared to the junior nurses. Incontrast, Delaney et al., (2011) stated that there was no association between years of experience and heart failure education principles knowledge.

Furthermore, the study done by Kalogirou et al. (2013) found that longer working experience corresponds with lower knowledge level. Seniority at work was a determinant contributing negatively to the knowledge level. This led Kalogirou et al., (2013) to suggest that the senior nurses were unlikely to attend academic sessions on heart failure self-management and are depended on outdated knowledge and past experiences. Accordingly, more research is necessary to better understand the effect between nurses' seniority and their heart failure knowledge.

(c) Nursing qualifications and knowledge on heart failure education principles

According to this research, associate charge nurses scored the highest with a mean score of 15.14 whereas the nurse educator scored the lowest with the mean score of 11. There is an association between nursing qualifications and knowledge on heart failure education principles as $p$-value was 0.046 . It should be noted that under nurse educator classification, there is only one (1) participant as there is only one nurse educator in the hospital. She is also the only nurse who holds a master's degree qualification and is retiring soon. The low score indicates that the nurse educator might be outdated with current medical practices. The results obtained on the nurse educator contradicts with Jankowska-Polanska et al., (2017) who found that nurses with low educational degree and long professional experience were more reluctant to read scholar literature and evidence-based nursing implementation. Associate charge nurses possessed lower degree qualification compared to the nurse educator, who were found to have stronger level of knowledge. The finding is consistent with Fowler (2012) whose results found that nurses with bachelor's degree have more initiative in advancing their nursing knowledge.

\section{Implications for Nursing Practice}

Nurses attending heart failure patients require a strong understanding of heart failure pathophysiology as drug therapy and self-care principles especially those related to weight gain, sodium intake, and fluid retention are crucial (Klabunde, 2007). Heart failure signs and symptoms with heart failure exacerbation such as weight gain need to be observed with other accompanying symptoms including vital signs, pulse oximetry, adventitious breath sounds, and the like. Preceptors and nurse educators play a crucial role in cultivating nurses' best practice in rendering care for heart failure patients. Heart failure protocols provide detailed direction in managing heart failure especially on daily weight management, weight comparison and weight change observation.

\section{Limitations}

This research was conducted only on one private hospital in Ipoh which is a relatively small city. Thus, the findings cannot possibly represent the larger population of heart failure patients or nurses in Perak or Malaysia or the wider world. The survey was dispersed to nurse managers for dissemination. Even though specific instructions were given to the managers and provided in the written study info sheet, but the 30-minutes time limit may not have been strictly adhered to. It is possible that some of the participants collaborated with each other by discussing the questionnaire. In addition, there is also a possibility the nurses utilized online resources to answer the questionnaire as the survey was not conducted in a controlled environment. Therefore, the outcome for general score and individual statements with correct responses may not be a true representation of the nurses' knowledge on heart failure. In addition, the number of participants were not evenly distributed, some departments such as nursing administrative, chemotherapy day care, maternity ward and diagnostic centre had less than 10 participants. As a result, the departments may not have been equally represented by the limited participants in the survey. Further, as the 
survey's participation is voluntary, a sizeable number of nurses may have been left out of the research, as a result it may not reflect the overall nurses' knowledge.

\section{RECOMMENDATIONS}

In future, more research is necessary to assess if continuing educational programs for nurses on specific topics on heart failure would minimize the deficits or gaps of knowledge. It would also be useful if additional studies are able to establish the ideal number of educational sessions and the maximum intervening period before the next session should be carried out for the purpose of maintaining an optimum level of nurses' knowledge in heart failure principles. It would also be beneficial for diploma and degree nursing colleges to review their curriculum to ensure heart failure education principles are comprehensively covered. Future research should also explore heart failure patient's ability to retain the information and knowledge given by the nurses and whether there are any methods or solutions in which the nurses are able to incorporate into their nursing care to make a difference. Furthermore, research is needed to study if there is any implication on heart failure patient education for the young and elderly patients. Elderly heart failure patients may have different learning and comprehension ability than the younger population. Thus a different standard or style of nursing care application of heart failure patient education may produce better outcomes.

\section{CONCLUSION}

The results of this study reveal that nurses who are working in this private hospital may not be adequately educated in heart failure self-management principles consistent with all previous studies. Developing an academic program tailored to meet the knowledge deficits with precision for continuing education may be the turning point needed to improve nurses' knowledge of heart failure self-management principles. The nurses' role to educate and promote heart failure self management skills to the patients cannot be overstated and they can only be successful when they have mastered the heart failure education principles. Given the increasing prevalence and chronic nature of heart failure, the public have increasingly high expectations of medical professionals to help them overcome the illness. One proven way to reduce unnecessary complications, hospital readmissions and better quality of life is through adherence to prescribed heart failure self-management guidelines under which the nurses are best positioned to make a real difference.

\section{Conflict of Interests} interest.

The authors declare that they have no conflict of

\section{ACKNOWLEDGEMENT}

The authors are thankful to the institutional authority for completion of the work.

\section{REFERENCES}

Albert, N. M. (2013). Parallel paths to improve heart failure outcomes: Evidence matters. American Journal of Critical Care, 22(4), pp 289-296.

Albert, N. M., Collier, S., Sumodi, V., Wilkinson, S., Hammel, J. P., Vopat, L., Willis, C. \& Bittel, B. (2002). Nurses's knowledge of heart failure education principles. Heart \& Lung: The Journal of Acute and Critical Care, 31(2), pp $102-112$.

Butrous, H. \& Hummel, S. L. (2016). Heart failure in older adults. Canadian Journal of Cardiology, 32(9), 1140-1147.

Chong, A. Y., Rajaratnam, R., Hussein, N. R. \& Lip, G. Y. (2003). Heart failure in a multiethnic population in Kuala Lumpur, Malaysia. European Journal of Heart Failure, 5(4), pp 569-574.

City Population (2010). Perak (State, Malaysia). Retrieved from: https://www.citypopulation.de/php/malaysiaadmin.php?adm1id=08

Cowie, M. R., Wood, D. A., Coats, A. J. S., Thompson, S. G., Suresh, V., Poole-Wilson, P. A. \& Sutton, G. C. (2000). Survival of patients with a new diagnosis of heart failure: a population-based study. Heart, 83(5), pp 505-510.

Delaney, C., Apostolidis, B., Lachapelle, L. \& Fortinsky, R. (2011). Home care nurses' knowledge of evidence-based education topics for management of heart failure. Heart \& Lung: The Journal of Acute and Critical Care, 40(4), pp 285-292. 
Fowler, S. (2012). Improving community health nurses' knowledge of heart failure education principles: a descriptive study. Home Healthcare Now, 30(2), pp 91-99.

Havas, K., Bonner, A. \& Douglas, C. (2016). Self-management support for people with chronic kidney disease: Patient perspectives. Journal of Renal Care, 42(1), pp 7-14.

Jankowska-Polanska, B., Brzykowska, M., Uchmanowicz, I., Lisiak, M. \& Rosinczuk, J. (2017). Polish Nurses' Knowledge of Heart Failure Self-Care Education Principles. Clinical Nurse Specialist, 31(3), E7-E13.

Kalogirou, F., Lambrinou, E., Middleton, N. \& Sourtzi, P. (2013). Cypriot nurses' knowledge of heart failure selfmanagement principles. European Journal of Cardiovascular Nursing, 12(2), pp 159-166.

Ministry of Health Malaysia (2014). Clinical Practice Guidelines Management of Heart Failure ( $3^{\text {rd }}$ ed.). Retrieved from: http://www.moh.gov.my/penerbitan/CPG/Management $\% 20$ of $\% 20 \% 20 H e a r t \% 20$ Failure $\%$ 202nd $\% 20 \%$ 20Edition.pdf

Ministry of Health Malaysia (2019). Clinical Practice Guidelines Management of Heart Failure. (4 ${ }^{\text {th }}$ edtion. Retrieved from https://www.malaysianheart.org/files/5cbd9a0ee09d9.pdf

Pichette, M., Liszkowski, M. \& Ducharme, A. (2017). Preoperative optimization of the heart failure patient undergoing cardiac surgery. Canadian Journal of Cardiology, 33(1), pp 72-79.

Polit, D. F. \& Beck, C. T. (2017). Nursing research: Ethics in nursing research.

Roussel, M. G. (2015). Improving nurses' knowledge of heart failure. Journal for Nurses in Professional Development, 31(4), pp 211-217.

Savarese, G. \& Lund, L. H. (2017). Global public health burden of heart failure. Cardiac Failure Review, 3(1), 7.

Sulzbach-Hoke, L. M., Kagan, S. H. \& Craig, K. (1997). Weighing behavior and symptom distress of clinic patients with CHF. MedSurg Nursing, 6(5), pp 288-295.

Sterne, P. P., Grossman, S., Migliardi, J. S. \& Swallow, A. D. (2014). Nurses' Knowledge of Heart Failure: Implications for Decreasing 30-Day ReAdmission Rates. Medsurg Nursing, 23(5).

Sundel, S. \& Ea, E. E. (2018). An Educational Intervention to Evaluate Nurses' Knowledge of Heart Failure. The Journal of Continuing Education in Nursing, 49(7), pp 315-321.

Washburn, S. C., Hornberger, C. A., Klutman, A. \& Skinner, L. (2005). Nurses' knowledge of heart failure education topics as reported in a small Midwestern community hospital. Journal of Cardiovascular Nursing, 20(3), pp 215-220.

Willette, E. W., Surrells, D., Davis, L. L. \& Bush, C. T. (2007). Nurses' Knowledge of Heart Failure Self-Management. Progress in Cardiovascular Nursing, 22(4), pp 190-195. 